\title{
The effect of acute heat exposure on rat pituitary corticotroph activation: the role of vasopressin
}

\author{
Nebojsa Jasnic ${ }^{1,3}$, Aleksandra Korac ${ }^{2,4}$, Ksenija Velickovic ${ }^{2,4}$, Igor Golic ${ }^{2,4}$, \\ Jelena Djordjevic $^{1}$, Sinisa Djurasevic ${ }^{1}$, Iva Djordjevic ${ }^{1}$, Predrag Vujovic ${ }^{1}$, \\ Gordana Cvijic ${ }^{1}$
}

\author{
${ }^{1}$ Institute of Physiology and Biochemistry, \\ ${ }^{2}$ Institute of Zoology, \\ ${ }^{3}$ Centre for Laser Microscopy, \\ ${ }^{4}$ Center for Electron Microscopy, \\ 1,2,3,4Faculty of Biology, University of Belgrade, Belgrade, Republic of Serbia
}

\begin{abstract}
The increased ambient temperature affects the function of hypothalamic-pituitary-adrenal (HPA) axis. Since the correlation among vasopressin (VP), adrenocorticotropic hormone (ACTH) and corticosterone (CORT) responses to various stressors have been long recognized, the aim of this study was to reveal the aforementioned hormones production and morphology of the pituitary gland after exposure to acute heat. Rats were exposed to high ambient temperature $\left(38^{\circ} \mathrm{C}\right)$ for 20 or 60 minutes. The circulating hormones were determined by an ELISA test or chemiluminescence's method. The results obtained show the elevation in ACTH and CORT secretion depending on the duration of heat exposure. The VP concentration increased only after prolonged exposure to heat $(60 \mathrm{~min})$. The pituitary morphology was examined by routine and fluorescent immunohistochemistry as well as electron microscopy. Observed changes in the anterior and posterior pituitary well corresponded to circulating hormones, regarding the volume density of ACTH-immunopositive cells, percentage of ACTH immunopositive area v. total area and number of VP-immunopositive containing varicose fibers per total area. Acute heat exposure also induced changes in shapes of ACTH-immunopositive cells. Cells appeared stellate with numerous slender cytoplasmic processes and degranulated, which is the most obvious after $20 \mathrm{~min}$. In addition, immunopositivity of endothelial and anterior pituitary cells for VP suggests its influence on ACTH secretion.
\end{abstract}

Key words: Heat stress, Vasopressin, ACTH, Corticosterone, Immunohistochemistry

\section{Introduction}

Changes in environmental temperature are very common threats, which have to be exceeded in the process of successful acclimatization of every endothermic organism. Previous studies have shown heat to be one of the most intense stressors when compared to cold, immobilization, crowding and fasting, as indicated by the highest rise of plasma $\mathrm{ACTH}$ and CORT concentrations following the exposure of animals to high ambient temperatures [1,2]. Rats, which are known as one of the most successful mammals in coping with extreme environmental con-

Correspondence: N. Jasnic, Faculty of Biology, University of Belgrade, Studentski Trg 3, 11000 Belgrade, Republic of Serbia; tel./fax.: (+38111) 2639064, e-mail: jasnicn@bio.bg.ac.rs ditions [3], are mostly used experimental model for studying that coping strategies. Their first reaction to the thermal stressors is primarily linked with sympatho-adrenomedullary system (SAS). However, when aversive stimuli cannot be controlled by this reaction, animals respond by the activation of the HPA axis. In spite of a great deal of information regarding the role of HPA axis in stress response, to date a question remains how the activity of the HPA axis can be specifically regulated.

The activation of the HPA axis results in the rapid increase in circulating $\mathrm{ACTH}$, with the subsequent rise in glucocorticoids, which is critical for successful acclimation [4]. Several authors suggested that corticotrophin-releasing hormone $(\mathrm{CRH})$ plays the major role in the regulation of pituitary corticotrophs activity [5-7]. However, according to others [8-10], ACTH 
response to stress is dependent on the interaction of both, CRH and VP secretion. VP may act as an important modulator of ACTH responses to stress by potentiating the stimulatory effect of its major regulator, CRH $[9,11,12]$. According to Aguilera and RabadanDiehl [13], parvocellular VP expression and secretion may be independent on the osmotic status, being increased during stress in order to potentiate ACTH release. On the other hand, VP of magnocellular origin is responsible for water conservation and regulation of its secretion depending on osmotic status [14]. However, the previous studies revealed that magnocellular VP could act as secretagogues for ACTH as well, reaching the anterior pituitary via several vascular pathways [15]. It was shown that VP binds to three $\mathrm{G}$ protein-coupled receptors, among which V1b receptors are primarily located at the corticotroph surface regulating ACTH secretion [16-21]. Although the role of VP in chronic stress response is well documented, it is still unclear how acute exposure to different types of stressors affects VP influence on ACTH secretion [22].

The aim of the present study was to elucidate production and secretion of the hormones related to HPA axis activation (VP, ACTH, CORT), as well as morpho-stereological changes of pituitary gland after exposure to acute heat.

\section{Material and methods}

Animals and treatments. The experiments were performed according to the rules of animal care proposed by Serbian Laboratory Animal Science Association (SLASA), which is the member of Federation of European Laboratory Animal Science Association (FELASA).

Male rats of Wistar strain (Rattus norvegicus), weighing $220 \pm 20 \mathrm{~g}$ were used for the experiments. The animals were acclimated to $22 \pm 1^{\circ} \mathrm{C}$, synchronized to a $12 \mathrm{~h}: 12 \mathrm{~h}$ light/dark regime with lights on at 06:00 $\mathrm{h}$ and lights off at 18:00 h, with free access to commercial rat food and a tap water. The rats were randomly divided into three groups (Control, Acute Heat 20min and Acute Heat $60 \mathrm{~min}$ ), each consisting of six animals. During the light phase of the light/dark cycle, rats in the Acute Heat (20min) and Acute Heat (60min) condition were transported into a temperature chamber (Sutjeska, Beograd, YUG) maintained at $38^{\circ} \mathrm{C}$ for a period of 20 or 60 minutes, respectively. Rats in the Control condition were left undisturbed in the housing facility during this time.

The animals were decapitated with a guillotine (HarwardApparatus, Holliston, MA, USA) without anesthesia immediately after the stress exposure. The blood was collected from the trunk, divided into 2 sets of tubes, with EDTA added to obtain plasma.

Biochemistry. Serum and plasma were frozen at $-80^{\circ} \mathrm{C}$ until the ACTH and VP determination. Serum corticosterone levels were determined by EIA kit (Immunodiagnostic Systems Ltd, UK) and the values were expressed as ngCORT $/ \mathrm{ml}$ serum. The plasma ACTH concentration was determined by a chemiluminescence method using an IMMULITE automatic analyzer (DPC, Los Angeles, CA). The values were expressed as $\mathrm{pgACTH} / \mathrm{ml}$ plasma. The serum VP concentration was obtained by commercially available ELISA test (R\&D Systems, Inc.) and the values were expressed as $\mathrm{pgVP} / \mathrm{ml}$ serum.
Immunohistochemistry. The pituitary glands were promptly dissected, weighed, fixed in Bouin's solution and embedded in paraffin wax according to the standard procedure. Serial sections of 5 $\mu \mathrm{m}$ were obtained at different levels of blocks following a ventralto-dorsal sequence. The sections were deparaffinized by xylene and rehydrated in graded ethanol. Endogenic peroxidase blocking was performed in 3\% hydrogen peroxide in phosphate-buffered saline (PBS) for $10 \mathrm{~min}$. After washing, the sections were incubated with primary antibody (ACTH, dilution 1:200, Chemicon International, Inc., Temecula, USA or AVP, dilution 1: 10000, Chemicon International, Inc., Temecula, USA), followed by PBS rinsing. After incubation with secondary antibody, immunoreactivity was detected by the avidin-biotin-peroxidase method (ABC kit) according to the manufacturer's protocol (Santa Cruz, CA, USA). The final reaction product was visualized with 3,3'- diaminobenzidine - tetrahydrochloride (Sigma - Aldrich, Taufkirchen, Germany). Sections were washed under running tap water, counterstained with hematoxylin and observed with a Leica DMLB (Austria) microscope. Negative controls were prepared by omitting the primary antibody.

Morphometry. The volume densities (Vv) of ACTH-immunopositive cells, as well as numerical density $(\mathrm{Na})$ of their nuclei per $\mu^{3}$ were measured using 50 test areas of the pituitary gland at the magnification of $\times 1000$, using the multipurpose test system M42, as described in previous papers $[23,24]$. Since rat ACTH cells are mononucleated, the numerical density of nuclei (Nv) corresponds to the number of cells per cubic millimeter. The volume density of ACTH-immunopositive cells was expressed as percentages of total pituitary cells.

Confocal laser microscopy. Sections were deparaffinized by xylene and rehydrated in graded ethanol. After washing in PBS, the sections were incubated with primary antibody (ACTH, dilution 1:200, Chemicon International, Inc., Temecula, USA or AVP, dilution 1:10000, Chemicon International, Inc., Temecula, USA) in PBS, followed by PBS rinsing. For fluorescent microscopy, secondary antibodies were labeled with rhodamine (for ACTH) or fluorescein (for VP). The images were obtained by the LSM 510 system with Axioscope FS2mot microscope (Carl Zeiss, Jena, Germany). The excitation wavelengths were set up at $488 \mathrm{~nm}$ (for fluorescein) and $543 \mathrm{~nm}$ (for rhodamine) in "single track" operation mode. The emission wavelengths were directed toward two different detection channels using a different combination of mirrors and filters (Ch1: LP 560 and Ch2: BP 505-530). The images were obtained using the Plan-Neofluar $\mathrm{x} 40 / 1.3$ Oil objective and used for the stereological analysis. The ImageJ software was used to evaluate the percentage of the surface covered by ACTHimmunopositive area v. total area, and for quantifying the number of VP-immunopositive containing varicose fibers per total area.

Electron microscopy. For electron microscopy, pituitary was fixed in $4 \%$ glutaraldehyde in $0.2 \mathrm{M}$ phosphate buffer at $4{ }^{\circ} \mathrm{C}$, washed in the same buffer, postfixed in $2 \%$ osmium tetroxide in the phosphate buffer, dehydrated in graded ethanol and embedded in Araldite (Fluka, Deisenhofen, Germany). The blocks were trimmed and cut with glass knives on an LKB III ultramicrotome (LKB, Bromna, Sweden). The thin sections $(30 \mathrm{~nm})$ were mounted on copper grids, stained with uranyl acetate and lead citrate and examined under a Philips CM12 (Philips, Eindhoven, The Netherlands) electron microscope.

Statistic analysis. Data were statistically evaluated by one way analysis of variance (ANOVA), using SigmaStat (Version 3.10) software. Holm-Sidak comparisons were performed when ANOVA was significant. The values were presented as the means \pm SEM of six animals and the level of significance was set at $p<0.05$. 


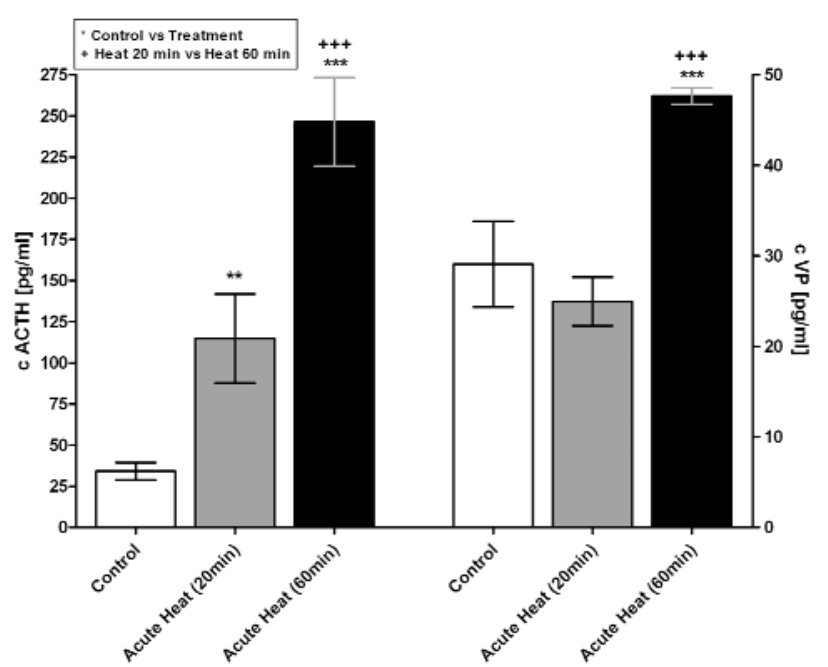

Fig. 1. The effect of acute exposure of rats to heat $\left(38^{\circ} \mathrm{C}\right)$ on ACTH and VP concentration in the blood; $* * p<0.01, * * * p<0.001$, $+++p<0.001$.

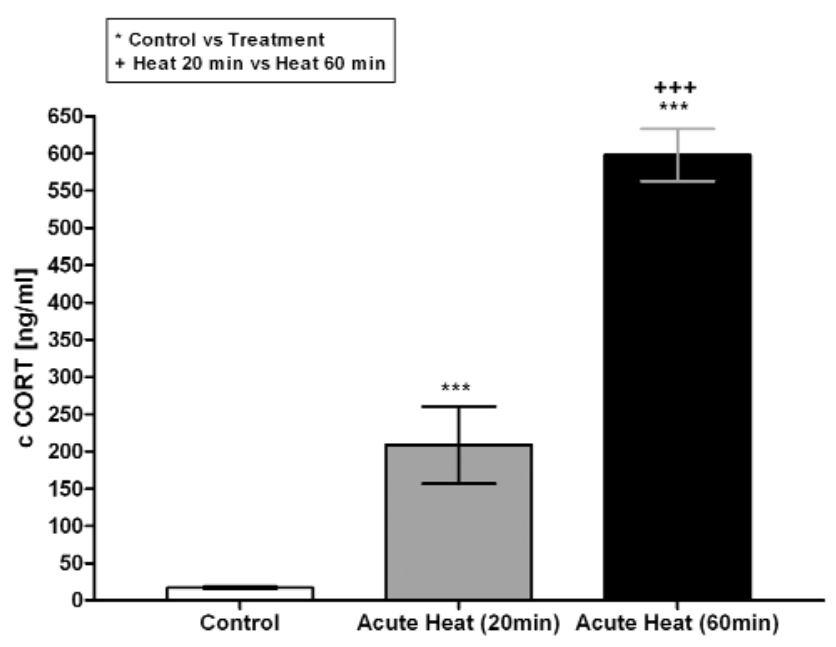

Fig. 2. The effect of acute exposure of rats to heat $\left(38^{\circ} \mathrm{C}\right)$ on CORT concentration in the blood; $* * * p<0.001,+++p<0.001$.

\section{Results}

The acute exposure of rats to heat for 20 min induced a significant increase in the circulating levels of ACTH concentration as compared to the control animals (Fig. $1, \mathrm{p}<0.01)$. After the exposure to heat for $60 \mathrm{~min}$, ACTH blood concentration increased further, being significantly higher in comparison to both, controls $(p<0.001)$ and the animals exposed to heat for $20 \mathrm{~min}$ $(p<0.001)$. However, the serum VP concentrations (Fig. 1) showed the significant increase only after a 60 min heat exposure $(\mathrm{p}<0.001)$, which was significantly higher than the serum VP concentration in the controls and the 20 min exposed animals $(p<0.001)$. The CORT serum concentration increased significantly after both, 20 and 60 min exposure $(p<0.001)$, being much high-
Table 1. Volume density of ACTH immunopositive cells (\%); ${ }^{\mathrm{a}} \mathrm{p}<0.001 ;{ }^{\mathrm{b}} \mathrm{p}>0.05$.

\begin{tabular}{|l|c|c|c|}
\hline & Control & $\begin{array}{c}\text { Heat } \\
20 \mathrm{~min}\end{array}$ & $\begin{array}{c}\text { Heat } \\
60 \mathrm{~min}\end{array}$ \\
\hline $\begin{array}{l}\text { Volume density of ACTH } \\
\text { immunopositive cells (\%) }\end{array}$ & $17.7 \pm 0.2$ & $7 \pm 0.1^{\mathrm{a}}$ & $13.8 \pm 0.2^{\mathrm{b}}$ \\
\hline
\end{tabular}

Table 2. Percentage of ACTH immunopositive area v. total area, ${ }^{\mathrm{a}} \mathrm{p}<0.05,{ }^{\mathrm{b}} \mathrm{p}<0.01$.

\begin{tabular}{|l|c|c|c|}
\hline & Control & $\begin{array}{c}\text { IIcat } \\
20 \mathrm{~min}\end{array}$ & $\begin{array}{c}\text { IIcat } \\
60 \mathrm{~min}\end{array}$ \\
\hline $\begin{array}{l}\text { Percentage of ACTH } \\
\text { immunopositive arca } v \\
\text { total area }\end{array}$ & $7.0 \pm 0.9$ & $4.6 \pm 1.4^{\mathrm{a}}$ & $9.7 \pm 1.8^{\mathrm{b}}$ \\
\hline
\end{tabular}

Table 3. The number of VP immunopositive varicose fibers per total area; ${ }^{\mathrm{a}} \mathrm{p}<0.001 ;{ }^{\mathrm{b}} \mathrm{p}>0.05$.

\begin{tabular}{|l|c|c|c|}
\hline & Control & $\begin{array}{c}\text { Ifeat } \\
20 \mathrm{~min}\end{array}$ & $\begin{array}{c}\text { IIeat } \\
60 \mathrm{~min}\end{array}$ \\
\hline $\begin{array}{l}\text { The number of VP } \\
\text { immunopositive } \\
\text { varicose fibers per } \\
\text { total area }\end{array}$ & $54.50 \pm 13.44$ & $8.33 \pm 3.56^{\mathrm{a}}$ & $47.33 \pm 12.42^{\mathrm{b}}$ \\
\hline
\end{tabular}

er after the longer exposure as compared to the $20 \mathrm{~min}$ and the control groups (Fig. 2, p<0.001).

Fig.ure 3 reveals the presence of a great number of ACTH-immunopositive cells in the anterior pituitary of control animals (Fig. 3-A). Although there were no changes in numerical density of their nuclei, after 20 min exposure to heat stress the volume density of ACTH-immunopositive cells decreased (Fig. 3-B, Table 1). The prolonged exposure to heat for $60 \mathrm{~min}$ partially restored the volume density in ACTHimmunopositive cells (Fig. 3-C, Table 1). This is in agreement with the observed higher circulating concentration of ACTH in these animals (Fig. 1, p<0.001). Ultrastructural examinations (Fig. 3-D, E, F) and confocal microscopy (Fig. 4-A, B, C) additionally support the changes in ACTH-immunopositive cells after heat exposure and clarify virtual changes in volume density. In the control group ACTH cells were clustered, ovoid shaped with centrally positioned euchromatic nucleus (Fig. 3D). Small uniform granules were regularly distributed along the cell membrane. Contrary, in heat exposed animals ACTH cells appeared stellate and showed numerous slender cytoplasmic processes (Fig. 3E, F). After $20 \mathrm{~min}$ exposures to heat stress some of ACTH cells were in a close contact with the dilated blood vessels showing a massive degranulation (Fig. 3E). With longer exposure to heat, the anterior pituitary blood vessels were found to be more pronounced. After 60 minutes (Fig. 3F) granules were 

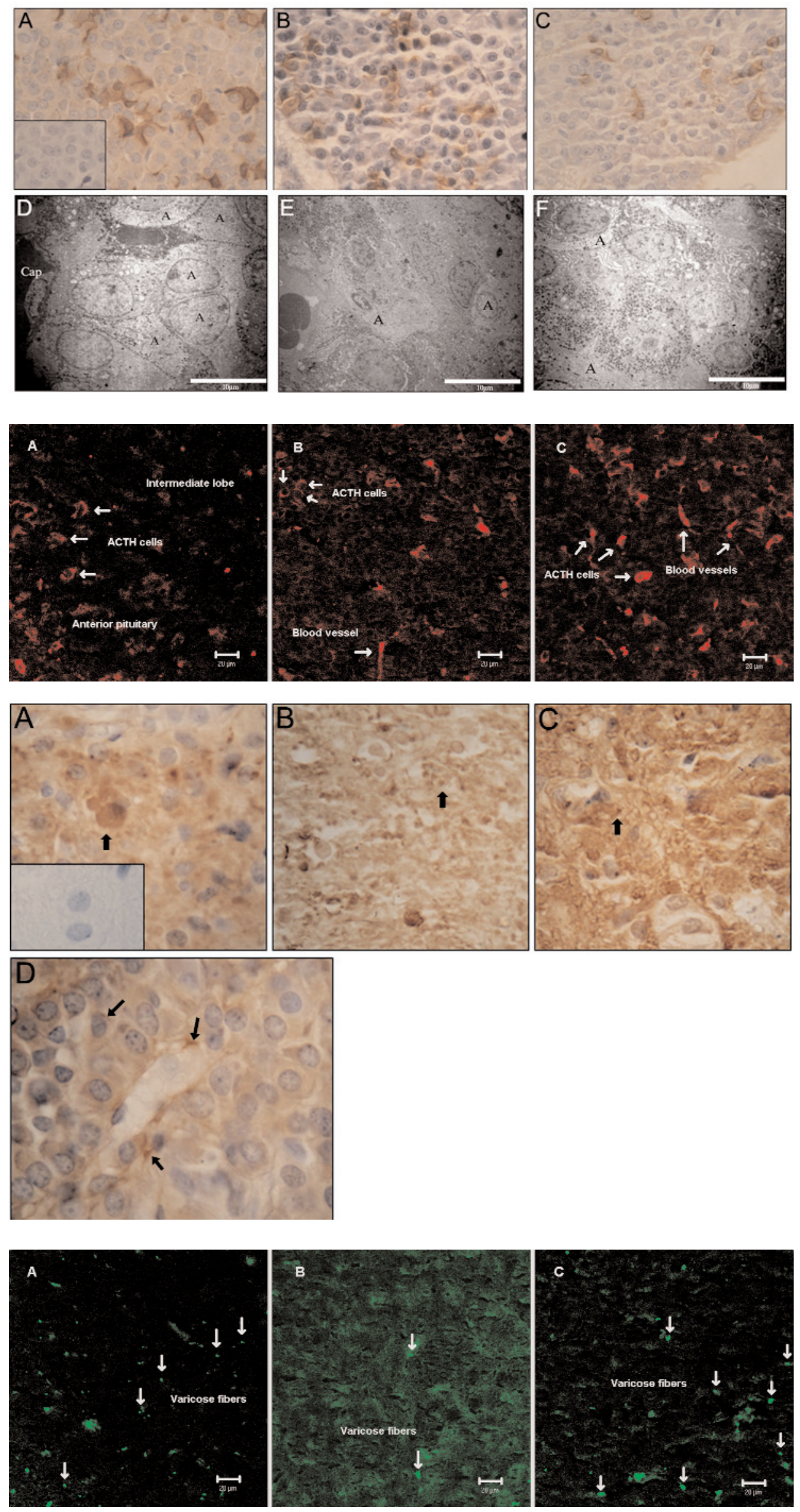

Fig. 6. The VP immunofluorescence in posterior pituitary glands of control (A), in $20 \mathrm{~min}(\mathbf{B})$ and $60 \mathrm{~min}$ heat exposed animals (C), bars $20 \mu \mathrm{m}$.

Fig. 3. Morphology (A-C) and ultrastructure (D-F) of ACTHimmunopositive cells in the anterior pituitary of control (A, D), in $20 \mathrm{~min}$ $(\mathrm{B}, \mathrm{E})$ and $60 \mathrm{~min}(\mathrm{C}, \mathrm{F})$ of heat stress. Magnification (A-C) $-\times 100$ orig., inset- nonimmune control. Original magnification (D-F) $\times 2650$, bars $-10 \mu \mathrm{m}$, Cap - capillary, A - ACTH-cells.

Fig. 4. The ACTH immunofluorescence in anterior pituitary glands of control (A), in $20 \mathrm{~min}$ (B) and 60 min heat exposed animals (C), bars $-20 \mu \mathrm{m}$.

Fig. 5. VP containing varicose fibers in the posterior pituitary glands of the control (A), 20 min (B) and 60 min heat exposed rats $(\mathbf{C})$ and in the anterior pituitary gland (D). Arrows indicate VP immunopositivity of pituitary plasma membrane, as well as blood vessel cells (D). Original magnification $(A-D)-\times 100$, inset nonimmune control.

(C) Polish Histochemical et Cytochemical Society

Folia Histochem Cytobiol. 2010:48(4): 510 (507-512) 10.2478/v10042-010-0071-6 
more numerous and sparsely distributed along the cell membrane, which was consistent with the significant increase in percent of ACTH-immunopositive cells v. total area (Table 2).

In the posterior pituitary the $\mathrm{VP}$ containing varicose fibers were more numerous in the control (Fig. 5A, Fig. 6A) and 60 min heat exposed animals (Fig. 5C; Fig. 6C) than in the 20 min group (Fig. 5B, Fig. 6B). This was further confirmed by confocal microscopy (Table 3 ), in the $60 \mathrm{~min}$ heat exposed animals the number of varicose fibers was similar to those of controls, but being much thicker (Fig. 1). In the anterior pituitary, we observed strong VP immunopositivity of pituitary plasma membrane, as well as blood vessel cells (Fig. 5D).

\section{Discussion}

In the present study, we showed the positive correlation between histomorphological and stereological changes in the pituitary gland and the blood concentration of hormones, which were synthesized in examined cells. Moreover, we found VP immunopositivity in plasma membrane of the anterior pituitary cells and blood vessel cells, suggesting the influence of VP on ACTH secretion.

The blood ACTH and VP levels expectedly increased during stress exposure, showing time dependency. The acute exposure of rats to heat for 20 min induced an increase in the circulating levels of $\mathrm{ACTH}$ concentration. After the exposure to heat for 60 min, ACTH blood concentration increased further, being higher as compared to both, controls and the animals exposed to heat for $20 \mathrm{~min}$. This is in agreement with morphological and stereological changes we obtained. Since the decreased density of ACTH cells did not mean necessarily that number of those cells was changed, it was of interest to reveal if this was due to secretion of ACTH or decreasing a number of ACTH-secreting cells. The numerical density of their nuclei confirmed that hormone secretion was in the background of those changes. This well corresponded to increased circulating ACTH levels suggesting that those changes were due to secretion of pre-synthesized hormone, while de novo synthesis of ACTH was needed for persistent elevation of circulating hormone. Those changes were followed by ultrastructural changes where cells became more stellate with numerous slender cytoplasmic processes. In the first period of degranulation, granules with pre-synthesized ACTH were regularly distributed along the cell membrane, suggesting intensive hormone secretion. After that period, the new granules appeared, this time sparsely distributed along the cell membrane. The pituitary gland remodeling occurred very fast; the processes of dynamic secretion and de novo synthesis of ACTH affected weigh and volume of the pituitary gland, since the anterior lobe weight and volume decreased and the posterior lobe increased in the pituitary glands of animals exposed to increased ambient temperature [25].

As far as VP is concerned, observed time-dependency regarding circulating VP levels is confirmed by immunohistochemistry, where the VP containing varicose fibers were more numerous in the control and in the $60 \mathrm{~min}$ heat exposed animals than in the $20 \mathrm{~min}$ group. Besides, in the $60 \mathrm{~min}$ heat exposed animals the varicose fibers were much thicker, indicating their increased secretory activity [26,27].

Although it is known that the anterior pituitary corticotrophs are directly affected by VP originating from parvocellular neurons of hypothalamic PVN, it has been shown that magnocellular VP could act as secretagogues for ACTH as well, reaching the anterior pituitary via three vascular pathways [15]. The first pathway is provided by the long portal vessels connecting the median eminence and the anterior pituitary. This pathway might enable VP released en passant from magnocellular axons to trigger ACTH secretion. The second pathway involves short portal vessels linking the posterior and anterior pituitary. Finally, VP can reach the portal blood following its secretion into the general blood circulation. This option appears unlikely to have significantly contributed to the ACTH response observed, since the concentration of VP is orders of magnitude higher in the portal blood than in the peripheral blood [28]. However, our data support the role of blood vessels in conducting of VP to the anterior pituitary, where it acts as ACTH secretagogues, since we observed the strong immunopositivity in plasma membrane of anterior pituitary cells, as well as in blood vessel cells (Fig. 5D), which haven't been previously shown by routine immunohistochemistry.

The increased blood VP levels clearly depict the activity of the magnocellular system disturbed by osmotic homeostasis during heat exposure. The VP circulating levels, mainly originated from magnocellular neurons of the hypothalamic paraventricular nucleus $(\mathrm{PVN})$, is increased during disturbed osmotic homeostasis [14]. Our results support this, since we obtained the increased VP circulating levels after exposing animals to acute heat for $60 \mathrm{~min}$ (Fig. 1). This might result from excessive water loss as judged by significant changes in the body weight. In conditions of elevated ambient temperature, rats must activate all mechanisms, including characteristic behavior, which could prevent the elevation of body temperature, and for maintaining or re-establishing temperature homeostasis. Thus, the intense salivation was accompanied by the excessive body licking and the spreading of saliva, presumably to enhance evaporation induced heat loss and lowering of the body temperature.

As a result of water loss and coping with increased ambient temperature, the body weight and the rectal 
temperature changed in a manner we have previously described [25]. However, significant decrease in body weights we have only observed after $60 \mathrm{~min}$ of heat exposure. It further suggests that the intensive water loss began after the $20^{\text {th }} \mathrm{min}$ of heat exposure (data were not shown).

Unfortunately, we couldn't manage to provide the evidence for VP binding on its receptors on corticotrophs. The lack of signal, in case of fluorescent immunohistochemistry, might be due to rapid VPV1bR action and a relatively low abundance of corticotroph membrane where these reactions occur. To elucidate this, our future experiments will include the examination of specific receptor-hormone interactions on the corticotroph membrane.

In conclusion, acute exposure to high ambient temperature induced significant morphological changes in both, anterior and posterior pituitary, accompanied by the elevation of circulating ACTH and VP. These changes were dependent on the duration of heat exposure. The VP presence in anterior pituitary strongly suggests its role in potentiating of ACTH secretion.

Acknowledgements: This work was supported by the Serbian Ministry of Science and Technological Development, the Project No 143050

\section{References}

[1] Bocheva A, Dzambazova E, Hadjiolova R, Traikov L, Mincheva R, Bivolarski I. Effect of Tyr-MIF-1 peptides on blood ACTH and corticosterone concentration induced by three experimental models of stress. Auton Autacoid Pharmacol. 2008;28:117-23.

[2] Djordjevic J, Cvijic G, Davidovic V. Different activation of ACTH and corticosterone release in response to various stressors in rats. Physiol Res. 2003;52:67-72.

[3] Donald RA, Wittert GA. Stress and corticotropin regulation. Curr Opin Endocrinol Diabetes. 1994;1:93-9.

[ 4] Dallman MF, Akana SF, Scribner KA, Bradbury MJ, Walker CD, Strack AM, et al. Stress, feedback and facilitation in the hypothalamo-pituitary-adrenal axix. J Neuroendocrinol. 1992;4:517-26.

[ 5] Gertz BJ, Contreras LN, McComb DJ, Kovacs K, Tyrrell JB, Dallman MF. Chronic administration of corticotropin-releasing factor increases pituitary corticotroph number. Endocrinology. 1987;120:381-8.

[ 6] Autelitano DJ, Blum M, Lopingco M, Allen RG, Roberts JL. Corticotropin-releasing factor differentially regulates anterior and intermediate pituitary lobe proopiomelanocortin gene transcription, nuclear precursor RNA and mature mRNA in vivo. Neuroendocrinology. 1990;51:123-30.

[7] Antoni FA. Hypothalamic control of adrenocorticotropin secretion: advances since the discovery of 41-residue corticotropin-releasing factor. Endocr Rev. 1986;7:351-78.

[ 8] Aguilera G. Regulation of pituitary ACTH secretion during chronic stress. Front Neuroendocrinol. 1994;15:321-50.

[ 9] Buckingham JC. Potentiation of hypothalamic corticotropin releasing activity by vasopressin: studies in the Brattleboro rat. Ann N Y Acad Sci. 1982;394:580-6.

[10] Mc Cann SM, Brobeck JR. Evidence for a role of the supraopticohypophyseal system in regulation of adrenocorticotrophin secretion. Proc Soc Exp Biol Med. 1954;87:318-24.
[11] Aguilera G, Subburaju S, Young S, Chen J. The parvocellular vasopressinergic system and responsiveness of the hypothalamic pituitary adrenal axis during chronic stress. Prog Brain Res. 2008;170:29-39.

[12] Antoni FA, Holmes MC, Jones MT. Oxytocin as well as vasopressin potentiate ovine $\mathrm{CRF}$ in vitro. Peptides. 1983;4:411-5.

[13] Aguilera G, Rabadan-Diehl C. Vasopressinergic regulation of the hypothalamic-pituitary-adrenal axis: implications for stress adaptation. Regul Pept. 2000;96:23-9.

[14] Stricker EM, Sved AF. Controls of vasopressin secretion and thirst: similarities and dissimilarities in signals. Physiol Behav. 2002;77:731-6.

[15] Engelmann M, Landgraf R, Wotjak CT. The hypothalamicneurohypophysial system regulates the hypothalamic-pituitary-adrenal axis under stress: an old concept revisited. Front Neuroendocrinol. 2004;25:132-49.

[16] Maybauer MO, Maybauer DM, Enkhbaatar P, Traber DL. Physiology of the vasopressin receptors. Best Pract Res Clin Anaesthesiol. 2008;22:253-63.

[17] Barberis C, Tribollet E. Vasopressin and oxytocin receptors in the central nervous system. Crit Rev Neurobiol. 1996;10:11954.

[18] Hernando F, Schoots O, Lolait SJ, Burbach JP. Immunohistochemical localization of the vasopressin $\mathrm{V} 1 \mathrm{~b}$ receptor in the rat brain and pituitary gland: anatomical support for its involvement in the central effects of vasopressin. Endocrinology. 2001;142:1659-68.

[19] Peter J, Burbach H, Adan RA, Lolait SJ, van Leeuwen FW, Mezey E, Palkovits M, Barberis C. Molecular neurobiology and pharmacology of the vasopressin/oxytocin receptor family. Cell Mol Neurobiol. 1995; 15:573-95.

[20] Stewart LQ, Roper JA, Scott Young W, 3rd, O'Carroll AM, Lolait SJ. The role of the arginine vasopressin Avp $1 \mathrm{~b}$ receptor in the acute neuroendocrine action of antidepressants. Psychoneuroendocrinology. 2008;33:405-15.

[21] Aguilera G. Corticotropin releasing hormone, receptor regulation and the stress response. Trends Endocrinol Metab. 1998;9:329-36.

[22] Makara GB, Mergl Z, Zelena D. The role of vasopressin in hypothalamo-pituitary-adrenal axis activation during stress: an assessment of the evidence. Ann $N$ Y Acad Sci. 2004;1018:151-61.

[23] Manojlovic Stojanoski M, Nestorovic N, Filipovic B, Milosevic V. ACTH-producing cells of 21-day-old rat fetuses after maternal dexamethasone exposure. Acta Histochem. 2004;106:199-205.

[24] Stevanovic D, Milosevic V, Starcevic VP, Severs WB. The effect of centrally administered ghrelin on pituitary ACTH cells and circulating ACTH and corticosterone in rats. Life Sci. 2007;80:867-872.

[25] Koko V, Djordjevic J, Cvijic G, Davidovic V. Effect of the acute heat stress on the rat pituitary gland. Morphological and stereological study. $J$ Therm Biol. 2006;31:394-99.

[26] Tanelian DL, Markin VS. Biophysical and functional consequences of receptor-mediated nerve fiber transformation. Biophys J. 1997;72:1092-1108.

[27] Ping Zhang P, Liu L, Xie CJ, Wang KH, Gao LZ, Ju G. Excitatory and inhibitory effects of prolactin release activated by nerve stimulation in rat anterior pituitary. Reprod Biol Endocrinol. 2009;7:154

[28] Plotsky PM. Pathways to the secretion of adrenocorticotropin: a view from the portal*. J Neuroendocrinol. 1991;3:1-9.

Submitted: 5 May, 2010 Accepted after reviews: 11 August, 2010 